\title{
Hypoxia-induced inhibition of the endocannabinoid system in glioblastoma cells
}

\author{
NAOTOSHI SUGIMOTO ${ }^{1,2}$, HIROAKI ISHIBASHI $^{3}$, HIROYUKI NAKAMURA $^{4}$, \\ AKIHIRO YACHIE $^{2}$ and TAKAKO OHNO-SHOSAKU ${ }^{5}$
}

\begin{abstract}
Departments of ${ }^{1}$ Physiology and ${ }^{2}$ Pediatrics, Graduate School of Medical Sciences, Kanazawa University, Kanazawa 920-8640; ${ }^{3}$ Department of Oral and Maxillofacial Surgery, Kanazawa Medical University, Uchinada 920-0293; ${ }^{4}$ Department of Public Health Pediatrics, Graduate School of Medical Sciences, Kanazawa University, Kanazawa 920-8640;

${ }^{5}$ Impairment Study, Graduate School of Medical Sciences, Kanazawa University, Kanazawa 920-0942, Japan
\end{abstract}

Received April 20,2017; Accepted September 26, 2017

DOI: 10.3892/or.2017.6048

\begin{abstract}
The endocannabinoid system plays an important role in the regulation of physiological and pathological conditions, including inflammation and cancer. Hypoxia is a fundamental phenomenon for the establishment and maintenance of the microenvironments in various physiological and pathological conditions. However, the influence of hypoxia on the endocannabinoid system is not fully understood. In the present study, we investigated the effects of hypoxia on the endocannabinoid system in malignant brain tumors. We subjected U-87 MG cells, derived from malignant glioblastoma, to hypoxia $\left(1.5 \% \mathrm{O}_{2}\right)$ for 3 days, and evaluated their viability and expression of endocannabinoid-related genes. Hypoxia decreased the expression of cannabinoid receptor 1 and the astrocyte marker glial fibrillary acidic protein, and increased the expression of vascular endothelial growth factor and cyclooxygenase-2, the enzyme responsible for the metabolism of endocannabinoids, in U-87 MG cells. Although cannabinoid receptor (CB) engagement induces cell death in U-87 MG cells in normoxic conditions, CB agonist-induced death was attenuated in hypoxic conditions. These results suggest that hypoxia modifies the endocannabinoid system in glioblastoma cells. Hypoxia-induced inhibition of the endocannabinoid system may aid the development of glioblastoma.
\end{abstract}

Correspondence to: Dr Naotoshi Sugimoto, Department of Physiology, Graduate School of Medical Science, Kanazawa University, 13-1 Takara-machi, Kanazawa, Ishikawa 920-8640, Japan

E-mail:ns@med.kanazawa-u.ac.jp

Abbreviations: CB, cannabinoid receptor; GFAP, glial fibrillary acidic protein; VEGF, vascular endothelial growth factor; COX-2, cyclooxygenase- 2

Key words: endocannabinoids, cannabinoid receptor, COX-2, GFAP, hypoxia, malignancy

\section{Introduction}

The endocannabinoid system, which includes the G-proteincoupled cannabinoid receptors 1 and 2 (CB1 and CB2) and their endogenous ligands (endocannabinoids), participates in a variety of physiological and pathological conditions, including inflammation and cancer (1-3). CB1 is abundantly expressed in the central nervous system, while CB2 is predominantly expressed by immune cells. Endogenous and exogenous cannabinoids exert anti-inflammatory and antitumor effects (1,4-9).

Glioma, the most common type of brain tumor, originates from differentiated glial cells of the central nervous system. Glial fibrillary acidic protein (GFAP) is a marker of glial differentiation (10). Low-grade malignancies have moderate expression of the protein, while high-grade malignancies have weak GFAP expression (11). Glioblastoma, a poorly differentiated type of glioma, is highly malignant and exhibits aggressive invasive growth. Existing treatments, including surgery, radiotherapy and chemotherapy, are largely unable to cure glioblastoma, which leads to death in most cases $(12,13)$. Therefore, new therapeutic approaches for treating glioblastoma are urgently needed. Recently, many synthetic agonists for cannabinoid receptors, which act on the endocannabinoid system, have been developed. Of these synthetic agonists, WIN 55,212-2 and KM-233 mimic the effects of endogenous cannabinoids and decrease cell viability in both glioma and glioblastoma $(14,15)$.

Various microenvironmental stresses modulate cell signaling in physiological and pathological conditions. Hypoxia, a type of stress that is fundamental in the microenvironment of a variety of solid tumors (16), has been implicated in the persistence and development of malignancies. Hypoxic stimuli prevent apoptosis and promote tumor invasion, metastasis and angiogenesis by regulating a variety of genes, including vascular endothelial growth factor (VEGF) and hypoxia-inducible factor $1 \alpha(17)$. Hypoxic regions are frequently found in glioblastoma $(18,19)$ and extensive hypoxia is associated with a worse prognosis (16).

In the present study, we examined the effects of hypoxia on the endocannabinoid system in U-87 MG human malignant glioblastoma cells. We found that hypoxia suppressed 
the expression of the genes encoding GFAP and cannabinoid receptors; increased the expression of the gene encoding cyclooxygenase (COX)-2, the enzyme that metabolizes endocannabinoids $(20,21)$, and attenuated cannabinoid receptor agonist (WIN 55,212-2)-induced cell death. Our findings provide insight into novel mechanisms by which hypoxia inhibits the endocannabinoid system and promotes the malignant phenotype of glioblastoma.

\section{Materials and methods}

Chemicals. WIN 55,212-2 and Dulbecco's modified Eagle's medium (DMEM) were obtained from Wako Pure Chemical Industries (Osaka, Japan). Fetal bovine serum (FBS) was obtained from Invitrogen (Carlsbad, CA, USA).

Preparation of primary rat glial cells. All experiments were performed in accordance with the guidelines set by the Animal Welfare Committee of Kanazawa University. Primary glial cells were prepared from newborn Sprague-Dawley rats as previously described (22-24). Briefly, following isoflurane anesthesia, rats were decapitated and cells were mechanically dissociated from the hippocampi and plated onto culture dishes (35 mm).

Cell culture. U-87 MG human malignant glioblastoma cells were provided by Dr Nakata (Kanazawa University, Kanazawa, Japan). U-87 MG and primary rat glial cells were maintained in DMEM containing $10 \% \mathrm{FBS}$ at $37^{\circ} \mathrm{C}$ in $5 \% \mathrm{CO}_{2}$. Then, cells were divided into 2 groups. The cells in the normoxia group were incubated in $5 \% \mathrm{CO}_{2}$ and $20 \% \mathrm{O}_{2}$, while the cells in the hypoxia group were maintained in $5 \% \mathrm{CO}_{2}$ and $1.5 \% \mathrm{O}_{2}$.

Reverse transcription polymerase chain reaction (RT-PCR). To evaluate the expression of human CB1 (CNRI), rat CB1 (Cnrl), human CB2 (CNR2), rat CB2 (Cnr2), human COX-1 (PTGS1), human COX-2 (PTGS2), human VEGF (VEGFA) and human GFAP (GFAP) mRNA in the cells, RT-PCR was performed as follows. Briefly, RNA was extracted from the cells and cDNA was generated using the reverse transcriptase ReverTra Ace ${ }^{\circledR}$ (Toyobo, Tokyo, Japan). We performed PCR-based, subtype-specific gene amplification with LA Taq (Takara, Tokyo, Japan) using the primers specified in Table I.

Cell proliferation and viability assays. Cell proliferation and viability were analyzed using the Cell Counting Kit-8 (CCK-8; Wako) as previously described (25). U-87 MG cells were seeded in 96-well plates at a density of $1 \times 10^{2}$ cells/well. After a 24-h incubation period, the cells were divided into 2 groups. The cells in the normoxia group were incubated in $5 \% \mathrm{CO}_{2}$ and $20 \% \mathrm{O}_{2}$, while the cells in the hypoxia group were maintained in $5 \% \mathrm{CO}_{2}$ and $1.5 \% \mathrm{O}_{2}$. After 3 days of continuous treatment, cells were allowed to recover in $5 \% \mathrm{CO}_{2}$ and $20 \% \mathrm{O}_{2}$ for $\sim 30 \mathrm{~min}$. Then, the cells were incubated with WST-8 (10 $\mu \mathrm{l}$ of WST-8 in $100 \mu \mathrm{l}$ of medium) for $3 \mathrm{~h}$ at $37^{\circ} \mathrm{C}$. The absorbance of the colored formazan product, generated by mitochondrial dehydrogenases in metabolically active cells, was recorded at $450 \mathrm{~nm}$. Cell proliferation and viability were expressed as a ratio of the absorbance in treated wells relative to that in untreated control wells.

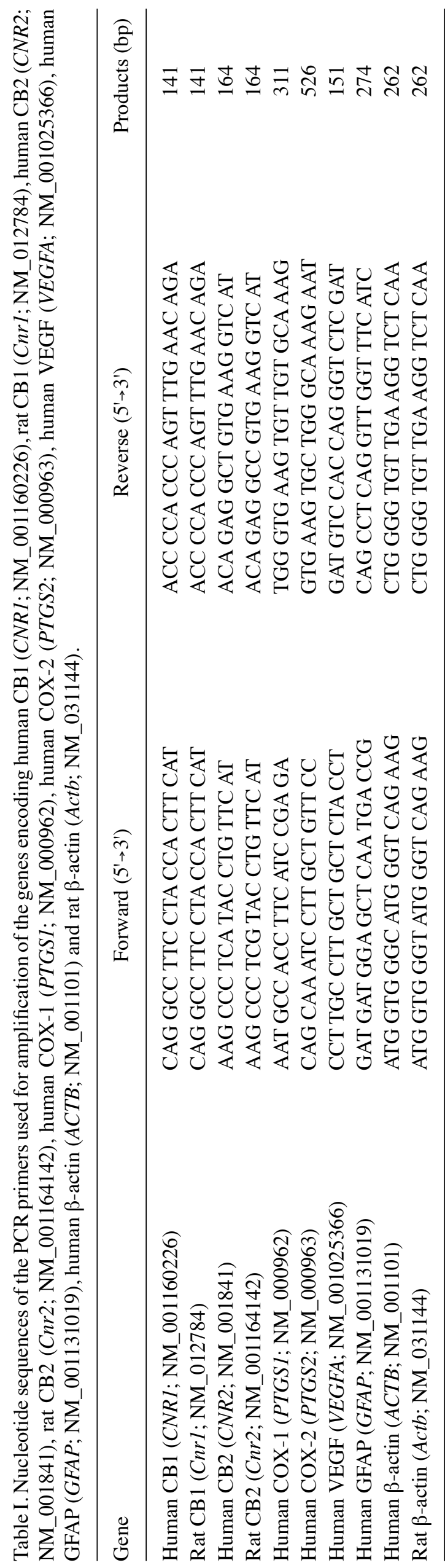




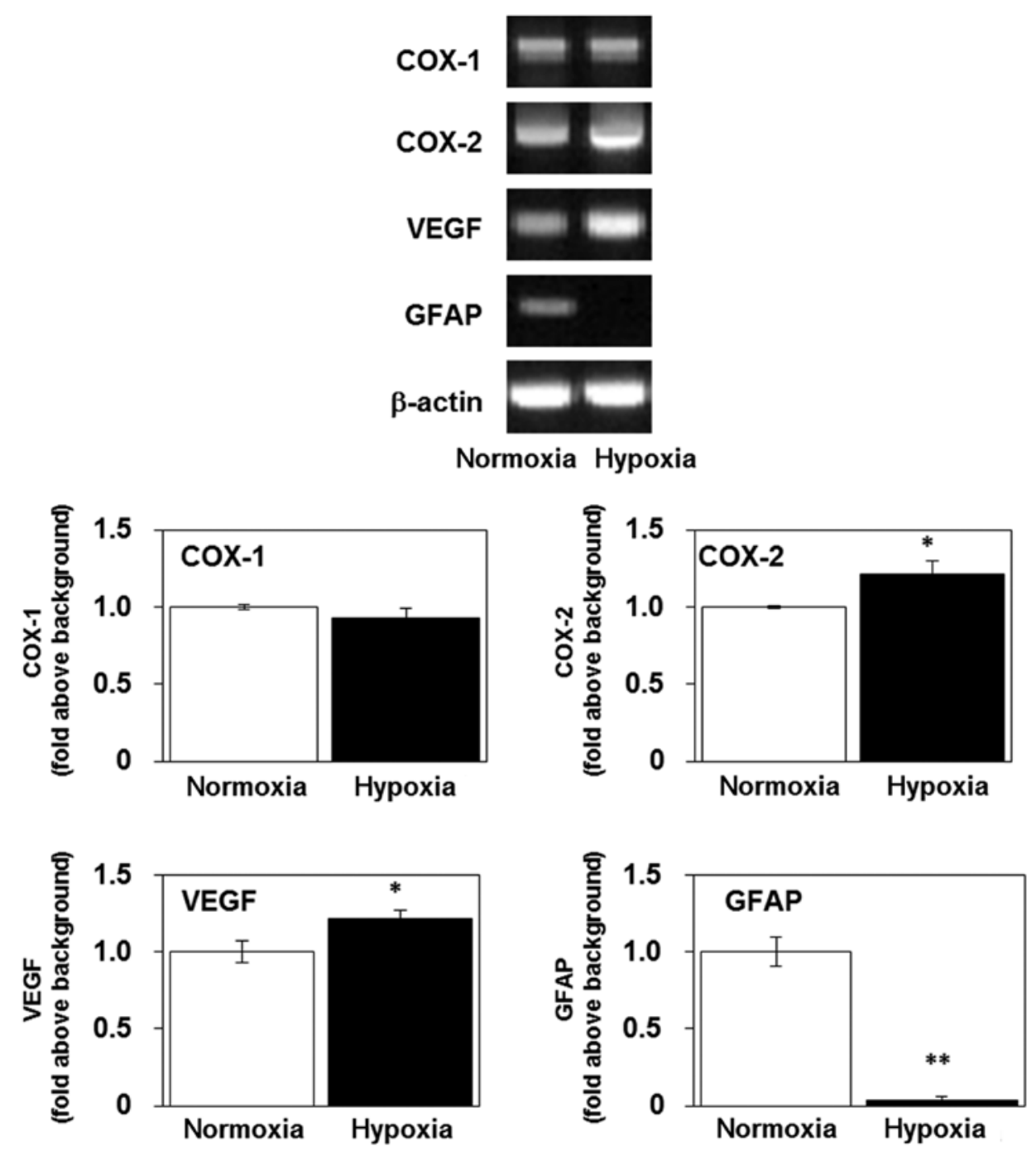

Figure 1. Hypoxia increases the expression of mRNA encoding COX-2 and VEGF, and decreases expression of GFAP mRNA, in U-87 MG cells. Cells were incubated in $20 \% \mathrm{O}_{2}$ (normoxia) or $1.5 \% \mathrm{O}_{2}$ (hypoxia) for 3 days. We evaluated the expression patterns of COX-1 (PTGS1), COX-2 (PTGS2), VEGF (VEGFA) and GFAP $(G F A P)$ by RT-PCR. The densities of the bands corresponding to COX-1, COX-2, VEGF, GFAP and $\beta$-actin were quantified by densitometry. Graphs depict mean \pm SEM from 3 independent experiments. Statistical analysis was conducted using Student's unpaired $\mathrm{t}$-test; ${ }^{*} \mathrm{P}<0.05$ and ${ }^{* *} \mathrm{P}<0.01$, compared with normoxic controls.

Cannabinoid receptor agonist treatment. Cells were treated with the cannabinoid receptor agonist WIN 55,212-2 in 5\% $\mathrm{CO}_{2}$ and $20 \% \mathrm{O}_{2}$ following a prior 3-day exposure to normoxia or hypoxia. After 2 days of agonist treatment, cell viability was analyzed using CCK-8 (Wako), as described above.

Statistical analysis. Data are presented as the mean \pm standard error of the mean (SEM) from at least 3 independent experiments. Statistical analysis was performed using Student's unpaired t-test or Kruskal-Wallis non-parametric analysis of variance (ANOVA) followed by a Bonferroni post hoc test, and results were considered statistically significant at $\mathrm{P}<0.05$.

\section{Results}

Hypoxia increases the levels of $m R N A$ encoding COX-2 and $V E G F$, and decreases the level of $m R N A$ encoding GFAP, in $U$-87 MG cells. We examined the effects of continuous exposure ( 3 days) to hypoxia on the expression of the genes for
COX-1, COX-2, VEGF and GFAP. Hypoxic exposure increased the levels of the mRNA encoding COX-2 and VEGF, but not COX-1, in the U-87 MG cells (Fig. 1), indicating that hypoxia activated inflammatory and angiogenic responses $(26,27)$. Notably, GFAP mRNA expression decreased over $72 \mathrm{~h}$ of hypoxia (Fig. 1), indicating that the cells had begun to dedifferentiate. Inflammation, angiogenesis and dedifferentiation are predictors of poor antitumor treatment responses and have previously been reported to potently activate tumor progression and invasion $(28,29)$.

Hypoxia does not affect cell viability and induces lamellipodia formation in U-87 MG cells. We previously showed that a 3-day exposure to hypoxia inhibited cell proliferation and viability in mouse fibroblast cells (30). In the present study, we investigated the effect of sustained exposure to hypoxia on U-87 MG cell proliferation and viability. We found that proliferation and viability were not significantly altered by hypoxia (Fig. 2), indicating that U-87 MG cells, unlike mouse fibroblast cells, are tolerant to hypoxia. 


\section{Hypoxia $\left(1.5 \% \mathrm{O}_{2}\right)$ for 3 days}

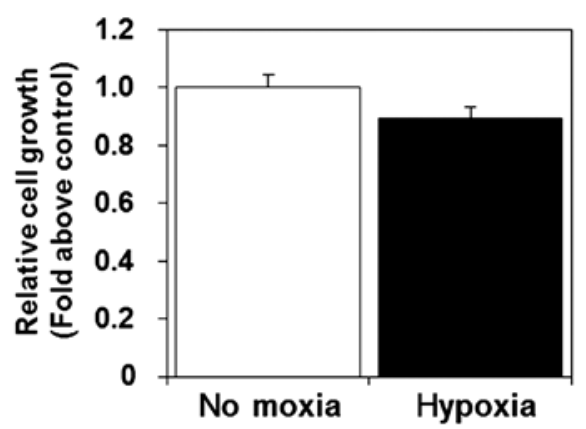

Figure 2. U-87 MG proliferation is unaltered by culture in sustained hypoxic conditions. Cells were incubated in $20 \% \mathrm{O}_{2}$ (normoxia) or $1.5 \% \mathrm{O}_{2}$ (hypoxia) for 3 days. Cell proliferation and viability were analyzed using the Cell Counting Kit- 8 . Bars depict mean \pm SEM from 3 independent experiments. Statistical analysis was conducted using Student's unpaired t-test.

Next, we examined the morphology of U-87 MG cells after sustained exposure to hypoxia. We found that lamellipodia formation occurred at the cell edges (Fig. 3), which is known to facilitate cell migration (31).

Hypoxia decreases the level of $m R N A$ encoding $C B 1$ in $U-87 M G$ cells. Next, we examined the expression of CB1 (CNR1) and CB2 (CNR2) mRNA in U-87 MG cells using
RT-PCR. The cannabinoid receptors facilitate the transduction of extracellular signals to the cytoplasm (2). The gene product encoding CB1 was detectable in U-87 MG cells, but the level of mRNA encoding CB2 was below the limit of detection (Fig. 4). Sustained 3-day exposure of U-87 MG cells to hypoxia decreased their expression of mRNA encoding CB1 (Fig. 4). These results indicate that hypoxia may regulate the cannabinoid system by modulating the expression of CB1.

Hypoxia attenuates cannabinoid receptor agonist-induced cell death in U-87 MG cells. Recently, cannabinoid receptor agonists have been shown to mimic the effects of endogenous cannabinoids and cause cell death in glioblastoma (15). Given the hypoxia-induced downregulation of cannabinoid receptor expression that we observed, we next examined the effects of sustained hypoxia on cannabinoid receptor agonist-induced cell death. We treated the cells with WIN 55,212-2 $(0.1,1.0$, or $10 \mu \mathrm{M})$ after an initial 3-day exposure to hypoxia $\left(1.5 \% \mathrm{O}_{2}\right)$ or normoxia $\left(20 \% \mathrm{O}_{2}\right)$. We analyzed cell proliferation and viability 2 days after treatment with WIN 55,212-2. WIN 55,212-2 treatment significantly reduced the viability of the cells under normoxic conditions in a dose-dependent manner, compared to the viability of the untreated normoxic controls (Fig. 5). However, the low doses of WIN 55,212-2 (0.1 or $1.0 \mu \mathrm{M})$ failed to induce cell death in the hypoxia group (Fig. 5). These results suggest that hypoxia confers tolerance to cannabinoid receptor agonist-induced cellular toxicity in glioblastoma.

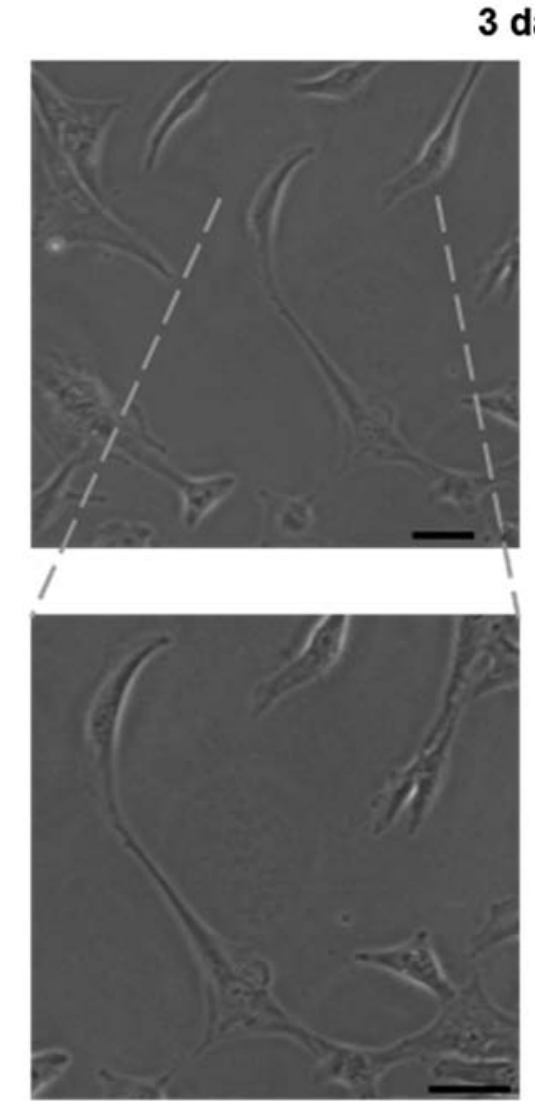

Normoxia

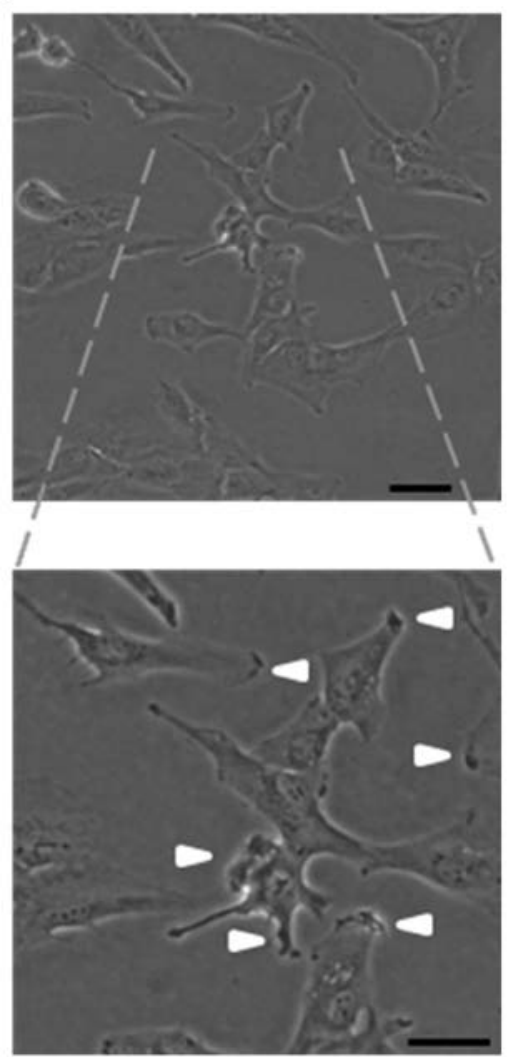

Hypoxia

Figure 3. Hypoxia induces lamellipodia formation in U-87 MG cells. Cells were incubated in $20 \% \mathrm{O}_{2}$ (normoxia) or $1.5 \% \mathrm{O}_{2}$ (hypoxia) for 3 days. Hypoxiainduced lamellipodia formation in cells. Results are representative of 3 independent experiments. White triangles, lamellipodia. Black scale bar, $25 \mu \mathrm{m}$. 

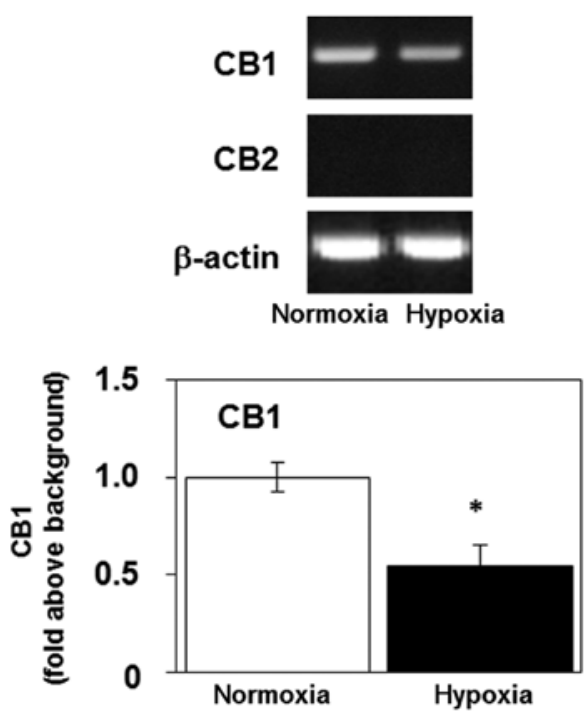

Figure 4. Hypoxia decreases the expression of mRNA encoding CB1 in U-87 MG cells. Cells were incubated in $20 \% \mathrm{O}_{2}$ (normoxia) or $1.5 \%$ $\mathrm{O}_{2}$ (hypoxia) for 3 days. The expression patterns of CB1 (CNR1) and CB2 (CNR2) were evaluated by RT-PCR. The densities of bands corresponding to $\mathrm{CB} 1$ and $\beta$-actin were quantified by densitometry. The graph presents mean \pm SEM from 3 independent experiments. Statistical analysis was conducted using Student's unpaired t-test; " $\mathrm{P}<0.05$, compared with normoxic control.

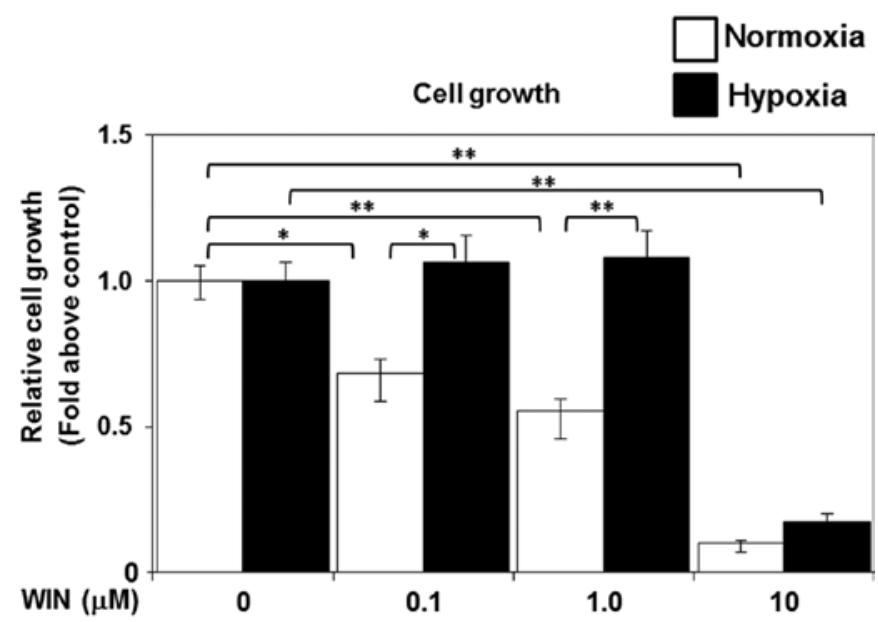

Figure 5. Effects of WIN 55,212-2 on the growth of U-87 MG cells with prior exposure to sustained normoxia or hypoxia. Cells were maintained in incubators under normoxic $\left(5 \% \mathrm{CO}_{2}\right.$ and $20 \% \mathrm{O}_{2}$ ) or hypoxic $\left(5 \% \mathrm{CO}_{2}\right.$ and $\left.1.5 \% \mathrm{O}_{2}\right)$ conditions. After 3 days of sustained treatment, cells were allowed to recover and cultured under normoxic conditions $\left(5 \% \mathrm{CO}_{2}\right.$ and $\left.20 \% \mathrm{O}_{2}\right)$ in the presence of the indicated doses of WIN 55,212-2 $(0,0.1,1.0$ or $10 \mu \mathrm{M})$ for 2 days. Then, cell proliferation and viability were analyzed using Cell Counting Kit-8. Bars represent mean \pm SEM. Statistical analysis was conducted using a Kruskal-Wallis non-parametric ANOVA followed by Bonferroni post hoc test; ${ }^{*} \mathrm{P}<0.05,{ }^{* *} \mathrm{P}<0.01$.

Hypoxia decreases the level of $m R N A$ encoding $C B 1$ and $C B 2$ in primary rat glial cells. We next examined the effects of hypoxia on the expression levels of CB1 $(\mathrm{Cnrl})$ and $\mathrm{CB} 2(\mathrm{Cnr} 2)$ mRNA in primary rat glial cells. Continuous 5-day exposure of primary glial cells to hypoxia decreased their expression of mRNA encoding both CB1 and CB2 (Fig. 6). These results indicate that hypoxia may regulate the expression levels of

\section{Primary glial cells}

CB2

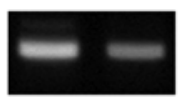

$\beta$-actin

Normoxia Hypoxia
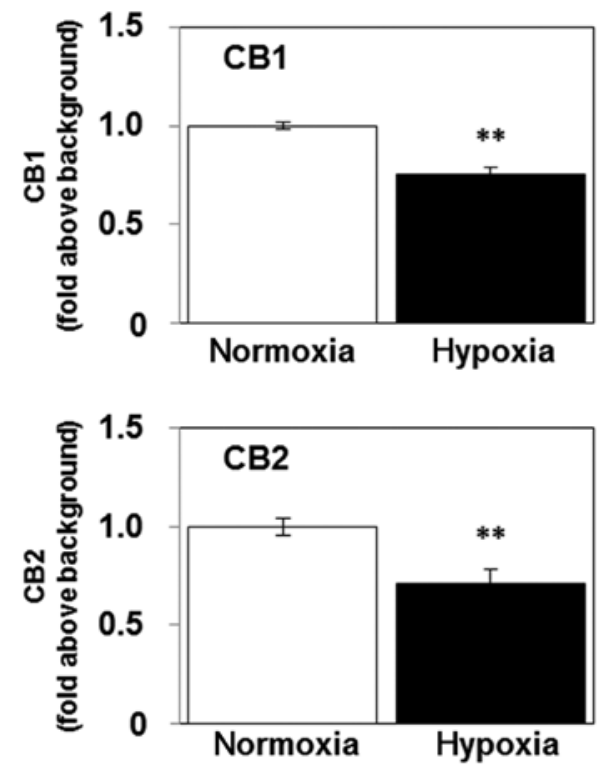

Figure 6. Hypoxia decreases the expression of mRNA encoding CB1 and $\mathrm{CB} 2$ in primary rat glial cells. Cells were incubated in $20 \% \mathrm{O}_{2}$ (normoxia) or $1.5 \% \mathrm{O}_{2}$ (hypoxia) for 3 days. The expression patterns of CB1 ( $\mathrm{Cnrl}$ ) and CB2 ( $\mathrm{Cnr} 2)$ were evaluated by RT-PCR. The densities of bands corresponding to $\mathrm{CB} 1, \mathrm{CB} 2$ and $\beta$-actin were quantified by densitometry. Bars represent mean \pm SEM from 3 independent experiments. Statistical analysis was conducted using Student's unpaired t-test; ${ }^{* *} \mathrm{P}<0.01$, compared with normoxic control.

cannabinoid receptors in normal glial cells as well as glioblastoma cells.

\section{Discussion}

Several lines of evidence show that cannabinoids influence a variety of physiological and pathological conditions $(2,8,32)$. Notably, cannabinoids can inhibit the growth of tumors, including glioblastoma, and have been proposed as potential antitumor agents $(7-9,14,33,34)$. In contrast, hypoxia is a common feature of solid tumors, and has been implicated in the persistence and development of malignancies (16). Hypoxic regions are frequently found in glioblastoma and hypoxia promotes a more malignant phenotype (16). However, the effects of hypoxia on the endocannabinoid system are not fully understood. In the present study, we presented novel findings that hypoxia downregulates mRNA encoding CB1, upregulates mRNA encoding COX-2, and prevented cannabinoid receptor agonist-induced cell death in U-87 MG cells. Our results suggest that hypoxia may promote the progression of glioblastoma by inhibiting the endocannabinoid system. 
We found that the cannabinoid receptor agonist WIN 55,212-2-induced glioblastoma cell death in a dosedependent manner. We also observed preferential expression of mRNA encoding CB1, in the absence of mRNA encoding CB2, in U-87 MG cells. We and other investigators have previously found that cannabinoid receptor agonists (WIN 55,212-2 and KM-233) suppress cell growth via CB1, as antagonists for CB1, but not CB2, reversed cannabinoid receptor agonist efficacy in U-87 MG cells $(7,14)$. We showed that hypoxia decreased the expression of mRNA encoding CB1 and inhibited WIN 55,212-2-induced cell death in U-87 MG cells, indicating a CB1-dependent mechanism of action. These results suggest that the activation of cannabinoid receptors in glioblastoma is essential for inhibition of tumor progression. Endocannabinoids are expressed in the brain (35), thus, it is possible that they suppress developing brain tumors via activation of cannabinoid receptors. Our present results suggest that hypoxia may counteract the beneficial antitumor effects of endocannabinoids by downregulating cannabinoid receptor expression in the brain.

Notably, several studies have indicated that activation of CB2 plays a more dominant role in the inhibition of glioma and glioblastoma progression than CB1 $(36,37)$. Although CB1 is predominantly expressed in the U-87 MG glioblastoma cells that we used in the present study, many glioma and glioblastoma cells express functional CB2 (38). To date, the effects of hypoxia on the expression of CB2 in glioma and glioblastoma cells have not been revealed. In the present study, we showed that hypoxia inhibited the expression of CB2 in normal primary glial cells. Further experiments are necessary to reveal whether hypoxia alters the expression of CB2 in glioma and glioblastoma cells.

Hypoxia increased the expression levels of mRNA encoding VEGF and COX-2, which are associated with the activation of angiogenic and inflammatory responses, in U-87 MG cells. Angiogenesis is necessary for tumor progression and inflammation induces tumor cell survival, growth and migration (39). COX-2 is known to metabolize endocannabinoids $(20,21)$. Thus, upregulation of COX-2 may inhibit endocannabinoid signaling by decreasing the concentration of endocannabinoids. Anandamide and 2-arachidonoylglycerol are major endocannabinoids that are produced, metabolized and kept at constant concentrations in the brain $(2,35)$. However, hypoxia upregulates the expression of COX-2, which may decrease the concentration of endocannabinoids in hypoxic regions of glioblastoma, resulting in promotion of tumor growth. Thus, hypoxia may facilitate the progression of glioblastoma by inhibiting the endocannabinoid system in two ways: i) downregulation of cannabinoid receptors; and ii) upregulation of the endocannabinoid-metabolizing enzyme COX-2.

Notably, we detected lower GFAP mRNA expression after $72 \mathrm{~h}$ of hypoxia, indicating dedifferentiation of astrocytes. Moreover, $72 \mathrm{~h}$ exposure to hypoxia significantly failed to induce cell death in the U-87 MG cells. Poorly differentiated and undifferentiated carcinomas are characterized by highly malignant tumors exhibiting aggressive invasive growth (40). We previously showed that $72 \mathrm{~h}$ exposure to hypoxia inducedcell death in mouse fibroblast cells (30). Thus, these results suggest that U-87 MG cells, unlike mouse fibroblast cells, may have increased hypoxia tolerance.
Hypoxia concomitantly downregulates the expression of mRNA encoding GFAP and CB1, but the relationship between dedifferentiation and endocannabinoid signaling is unknown. Further experiments are necessary to reveal the relationship between them.

Lamellipodia are formed by actin assembly at the edge of a cell in the direction of migration. Phosphoinositide 3-kinase (PI3K) activation is known to induce lamellipodia formation (31). Hypoxia activates PI3K (41) and induces lamellipodia formation, as shown Fig. 3, which may facilitate tumor invasion.

Hypoxia inhibited the expression of mRNA encoding CB1 in primary glial cells, as well as in U-87 MG cells, indicating that hypoxia-induced downregulation of CB1 is common to normal glial and malignant glioma cells. Although hypoxiainduced inhibition of the endocannabinoid system is thought to promote cancer progression, its role in normal glial cells has not been revealed. Further experiments are necessary to elucidate the effects of endocannabinoid inhibition mediated by hypoxia in healthy glial cells.

In conclusion, the present study demonstrated that hypoxia downregulates CB1 receptors, upregulates COX-2 and prevents cannabinoid receptor agonist-induced cell death in U-87 MG cells in vitro. These results suggest that hypoxia may promote brain tumor progression by inhibiting the endocannabinoid system.

\section{Acknowledgements}

The present study was supported by Grants-in-Aid for Science and Culture (nos. 23500466, 25282021, 26430013, 26650173, 15KT0003, 16H005513 and 16K13013) from the Ministry of Education, Culture, Sports, Science and Technology of Japan. This manuscript has been edited and corrected by an experienced proofreader who is a native speaker of English and who is under the direct supervision of Honyaku Center Inc. (Tokyo, Japan).

\section{References}

1. Gui H, Tong Q, Qu W, Mao CM and Dai SM: The endocannabinoid system and its therapeutic implications in rheumatoid arthritis. Int Immunopharmacol 26: 86-91, 2015.

2. Kano M, Ohno-Shosaku T, Hashimotodani Y, Uchigashima M and Watanabe M: Endocannabinoid-mediated control of synaptic transmission. Physiol Rev 89: 309-380, 2009.

3. Ligresti A, De Petrocellis L and Di Marzo V: From phytocannabinoids to cannabinoid receptors and endocannabinoids: Pleiotropic physiological and pathological roles through complex pharmacology. Physiol Rev 96: 1593-1659, 2016.

4. Cabral GA and Griffin-Thomas L: Cannabinoids as therapeutic agents for ablating neuroinflammatory disease. Endocr Metab Immune Disord Drug Targets 8: 159-172, 2008.

5. Cabral GA, Rogers TJ and Lichtman AH: Turning over a new leaf: Cannabinoid and endocannabinoid modulation of immune function. J Neuroimmune Pharmacol 10: 193-203, 2015.

6. Centonze D, Finazzi-Agrò A, Bernardi G and Maccarrone M: The endocannabinoid system in targeting inflammatory neurodegenerative diseases. Trends Pharmacol Sci 28: 180-187, 2007.

7. Echigo R, Sugimoto N, Yachie A and Ohno-Shosaku T: Cannabinoids inhibit peptidoglycan-induced phosphorylation of NF- $\kappa$ B and cell growth in U87MG human malignant glioma cells. Oncol Rep 28: 1176-1180, 2012.

8. Guindon J and Hohmann AG: The endocannabinoid system and cancer: Therapeutic implication. Br J Pharmacol 163: 1447-1463, 2011. 
9. Salazar M, Carracedo A, Salanueva IJ, Hernández-Tiedra S, Lorente M, Egia A, Vázquez P, Blázquez C, Torres S, García S, et al: Cannabinoid action induces autophagy-mediated cell death through stimulation of ER stress in human glioma cells. J Clin Invest 119: 1359-1372, 2009.

10. Singh R, Singh B and Malhotra SK: A new 'marker' protein for astrocytes. Biosci Rep 6: 73-80, 1986.

11. Dell'albani P, Rodolico M, Pellitteri R, Tricarichi E, Torrisi SA, D'Antoni S, Zappia M, Albanese V, Caltabiano R, Platania N, et al: Differential patterns of NOTCH1-4 receptor expression are markers of glioma cell differentiation. Neuro Oncol 16: 204-216, 2014.

12. Burnet NG, Lynch AG, Jefferies SJ, Price SJ, Jones PH, Antoun NM, Xuereb JH and Pohl U: High grade glioma: Imaging combined with pathological grade defines management and predicts prognosis. Radiother Oncol 85: 371-378, 2007.

13. Daumas-Duport C, Scheithauer B, O'Fallon J and Kelly P: Grading of astrocytomas. A simple and reproducible method. Cancer 62: 2152-2165, 1988.

14. Gurley SN, Abidi AH, Allison P, Guan P, Duntsch C, Robertson JH, Kosanke SD, Keir ST, Bigner DD, Elberger AJ, et al: Mechanism of anti-glioma activity and in vivo efficacy of the cannabinoid ligand KM-233. J Neurooncol 110: 163-177, 2012.

15. Ortega A, Rangel-López E, Hidalgo-Miranda A, Morales A, Ruiz-García E, Meneses-García A, Herrera-Gómez A, Aguilar-Ponce JL, González-Herrera IG, Guevara-Salazar P, et al: On the effects of CP 55-940 and other cannabinoid receptor agonists in C6 and U373 cell lines. Toxicol In Vitro 29: 1941-1951, 2015.

16. Yang L, Lin C, Wang L, Guo $\mathrm{H}$ and Wang $\mathrm{X}$ : Hypoxia and hypoxia-inducible factors in glioblastoma multiforme progression and therapeutic implications. Exp Cell Res 318: 2417-2426, 2012

17. Horiuchi A, Imai T, Shimizu M, Oka K, Wang C, Nikaido T and Konishi I: Hypoxia-induced changes in the expression of VEGF, HIF-1 alpha and cell cycle-related molecules in ovarian cancer cells. Anticancer Res 22: 2697-2702, 2002.

18. Bao B, Azmi AS, Ali S, Ahmad A, Li Y, Banerjee S, Kong D and Sarkar FH: The biological kinship of hypoxia with CSC and EMT and their relationship with deregulated expression of miRNAs and tumor aggressiveness. Biochim Biophys Acta 1826 272-296, 2012

19. Kawai N, Maeda Y,Kudomi N, Miyake K, Okada M, Yamamoto Y, Nishiyama Y and Tamiya T: Correlation of biological aggressiveness assessed by ${ }^{11} \mathrm{C}$-methionine PET and hypoxic burden assessed by ${ }^{18} \mathrm{~F}$-fluoromisonidazole PET in newly diagnosed glioblastoma. Eur J Nucl Med Mol Imaging 38: 441-450, 2011.

20. Alhouayek M and Muccioli GG: COX-2-derived endocannabinoid metabolites as novel inflammatory mediators. Trends Pharmacol Sci 35: 284-292, 2014.

21. Hermanson DJ, Gamble-George JC, Marnett LJ and Patel S: Substrate-selective COX-2 inhibition as a novel strategy for therapeutic endocannabinoid augmentation. Trends Pharmacol Sci 35: 358-367, 2014

22. McCarthy KD and de Vellis J: Preparation of separate astroglial and oligodendroglial cell cultures from rat cerebral tissue. J Cell Biol 85: 890-902, 1980.

23. Ohno-Shosaku T, Maejima T and Kano M: Endogenous cannabinoids mediate retrograde signals from depolarized postsynaptic neurons to presynaptic terminals. Neuron 29: 729-738, 2001.
24. Sugimoto N, Leu H, Inoue N, Shimizu M, Toma T, Kuroda M, Saito T, Wada T and Yachie A: The critical role of lipopolysaccharide in the upregulation of aquaporin 4 in glial cells treated with Shiga toxin. J Biomed Sci 22: 78, 2015.

25. Leu H, Sugimoto N, Shimizu M, Toma T, Wada T, Ohta K and Yachie A: Tumor necrosis factor- $\alpha$ modifies the effects of Shiga toxin on glial cells. Int Immunopharmacol 38: 139-143, 2016.

26. Mongiardi MP: Angiogenesis and hypoxia in glioblastoma: A focus on cancer stem cells. CNS Neurol Disord Drug Targets 11: 878-883, 2012

27. Wang S, Liu Z, Wang L and Zhang X: NF-kappaB signaling pathway, inflammation and colorectal cancer. Cell Mol Immunol 6: 327-334, 2009.

28. Friedmann-Morvinski D: Glioblastoma heterogeneity and cancer cell plasticity. Crit Rev Oncog 19: 327-336, 2014.

29. Sowers JL, Johnson KM, Conrad C, Patterson JT and Sowers LC: The role of inflammation in brain cancer. Adv Exp Med Biol 816: 75-105, 2014

30. Sugimoto N, Shido O, Matsuzaki K, Katakura M, Hitomi Y, Tanaka M, Sawaki T, Fujita Y, Kawanami T, Masaki Y, et al: Long-term heat exposure prevents hypoxia-induced apoptosis in mouse fibroblast cells. Cell Biochem Biophys 70: 301-307, 2014.

31. Sugimoto N, Takuwa N, Yoshioka K and Takuwa Y: Rho-dependent, Rho kinase-independent inhibitory regulation of Rac and cell migration by $\mathrm{LPA}_{1}$ receptor in $\mathrm{G}_{\mathrm{i}}$-inactivated $\mathrm{CHO}$ cells. Exp Cell Res 312: 1899-1908, 2006.

32. Klein TW: Cannabinoid-based drugs as anti-inflammatory therapeutics. Nat Rev Immunol 5: 400-411, 2005.

33. Guzmán M: Cannabinoids: Potential anticancer agents. Nat Rev Cancer 3: 745-755, 2003.

34. Sarfaraz S, Adhami VM, Syed DN, Afaq F and Mukhtar H: Cannabinoids for cancer treatment: Progress and promise. Cancer Res 68: 339-342, 2008.

35. Zoerner AA, Gutzki FM, Batkai S, May M, Rakers C, Engeli S, Jordan J and Tsikas D: Quantification of endocannabinoids in biological systems by chromatography and mass spectrometry: A comprehensive review from an analytical and biological perspective. Biochim Biophys Acta 1811: 706-723, 2011.

36. Blázquez C, Salazar M, Carracedo A, Lorente M, Egia A, González-Feria L, Haro A, Velasco G and Guzmán M: Cannabinoids inhibit glioma cell invasion by down-regulating matrix metalloproteinase-2 expression. Cancer Res 68: 1945-1952, 2008.

37. Rocha FC, Dos Santos Júnior JG, Stefano SC and da Silveira DX: Systematic review of the literature on clinical and experimental trials on the antitumor effects of cannabinoids in gliomas. J Neurooncol 116: 11-24, 2014.

38. De Jesús ML, Hostalot C, Garibi JM, Sallés J, Meana JJ and Callado LF: Opposite changes in cannabinoid CB1 and CB2 receptor expression in human gliomas. Neurochem Int 56: 829-833, 2010.

39. Ono M: Molecular links between tumor angiogenesis and inflammation: Inflammatory stimuli of macrophages and cancer cells as targets for therapeutic strategy. Cancer Sci 99: 1501-1506, 2008.

40. Dai C and Holland EC: Astrocyte differentiation states and glioma formation. Cancer J 9: 72-81, 2003.

41. Muz B, de la Puente P, Azab F and Azab AK: The role of hypoxia in cancer progression, angiogenesis, metastasis, and resistance to therapy. Hypoxia 3: 83-92, 2015. 